\title{
Clostridium Botulinum EN MUESTRAS DE SUELO Y LODO DE LA REPÚBLICA DEL PARAGUAY
}

\author{
Clostridium Botulinum IN SOIL AND MUD SAMPLES OF THE REPUBLIC OF PARAGUAY \\ Ortiz R, $\mathbf{N}^{1,2}$
}

\begin{abstract}
${ }^{1}$ Departamento de Microbiología e Inmunología, Cátedras de Microbiología e Inmunología y de Enfermedades Infecciosas y Contagiosas. Facultad de Ciencias Veterinarias, Universidad Nacional de Asunción - San Lorenzo - Paraguay

${ }^{2}$ Servicio Nacional de Calidad y Salud Animal - San Lorenzo - Paraguay
\end{abstract}

RESUMEN. Muestras de suelo y lodo de la República del Paraguay fueron colectadas para el estudio de la presencia y distribución de Clostridium botulinum. Un total de 54 muestras de 12 departamentos del país se han examinado, de las cuales 36 fueron obtenidas de establecimientos ganaderos, 9 del río Paraguay, 6 del lago Ypacaraí y 3 de pantanos. Las muestras fueron examinadas según el procedimiento descrito por Smith y Moryson (1975), cultivadas en medio de carne cocida e incubadas a $30^{\circ} \mathrm{C}$ durante 6 a 8 días; el sobrenadante filtrado de cada muestra fue inoculado vía intraperitoneal en ratones, para determinar la presencia de toxinas de Clostridium botulinum. Los filtrados positivos fueron sometidos a la prueba de neutralización con antitoxinas específicas e inoculados en ratones, para la tipificación de las toxinas. La presencia de toxinas fue demostrada en 18 (33\%) del total de muestras estudiadas; siendo la toxina tipo A detectada en $1(1,9 \%)$ muestra, el tipo C en $6(11,1 \%)$ muestras y el tipo D en $7(13 \%)$ muestras, la toxicidad producida por los filtrados de las 4 muestras restantes fue débil para permitir la identificación del tipo de toxina por la prueba de neutralización en ratones.

Palabras Clave: Clostridium botulinum, toxina, bovino, suelo, Paraguay.

\begin{abstract}
Soil and mud samples were collected for the study of the presence and distribution of Clostridium botulinum. A total of 54 samples from 12 departments of the country were examined, of these, 36 were collected from livestock farms, 9 from the Paraguay river, 6 from Ypacaraí lake, 3 from marshes. Samples were examined following the procedure described by Smith and Moryson (1975), inoculated in cooked meat medium and incubation at $30^{\circ} \mathrm{C}$ for 6 to 8 days; filtered supernatant from each sample was inoculated in mice to determine the presence of Clostridium botulinum toxins. Positive filtrates were subject to neutralization test using specific antitoxins, inoculated into mice for toxin typing. The presence of toxin was demonstrated in $18(33 \%)$ of the total number of samples studied; toxin type A was detected in 1 (1.9\%), type C in $6(11.1 \%)$ and type D in 7 (13\%) samples. The toxicity produced by the filtrates of 4 samples was weak to be typed by the toxin neutralization test in mice.
\end{abstract}

Keywords: Clostridium botulinum, toxin, bovine, soil, Paraguay.

doi: http://dx.doi.org/10.18004/compend.cienc.vet.2015.05.01.14-19

Dirección para correspondencia: Dra. Nelly Ortiz - Departamento de Microbiología e Inmunología, Cátedras de Microbiología e Inmunología y de Enfermedades Infecciosas y Contagiosas. Facultad de Ciencias Veterinarias - Universidad Nacional de Asunción - Casilla de Correo Nº1061 - Ruta Mcal. Estigarribia Km 10,5 - Campus Universitario - San Lorenzo - Paraguay

E-Mail: nortiz@vet.una.py

Recibido: 26 de marzo de 2015 / Aceptado: 08 dejunio de 2015 


\section{INTRODUCCIÓN}

Clostridium botulinum es una bacteria anaerobia, esporulada, ampliamente distribuida en suelos y agua en el mundo; produce una potente neurotoxina cuya ingestión ocasiona el botulismo, enfermedad que afecta a varias especies animales y al hombre. Se clasifica en siete tipos basados en la especificidad antigénica de sus toxinas (A, B, C, D, E, F, G).

La enfermedad ha ocasionado importante mortandad de bovinos en varios países, especialmente en aquellos con extensos establecimientos ganaderos como Brasil $(1,2,3)$ donde se la denomina "Doença da mano dura"; Argentina, donde es conocida como el "Mal del Aguapey" por brotes ocurridos en el noreste de la provincia de Corrientes $(4,5)$; Sudáfrica (6) y otros.

Casos de botulismo bovino también fueron reportados en Paraguay siendo el C. botulinum tipo D el identificado en las muestras colectadas de los animales afectados (7). Otros casos de mortalidad de bovinos han sido denunciados en diversos establecimientos del Paraguay, especialmente en los Departamentos de Paraguarí, Concepción, Amambay y San Pedro de la Región Oriental, donde los animales, de diferentes categorías, morían por causas desconocidas, pereciendo en general, durante la estación lluviosa, aunque también han ocurrido durante otras épocas del año, pero en menor escala.

A pesar de los eventos mencionados y el conocimiento acerca de la presencia y distribución de $C$. botulinum en el suelo paraguayo, existe aún escasa información al respecto. No obstante, en una investigación realizada por Yamakawa et al (1990) se demostró la presencia de $C$. botulinum en 7 de las 17 muestras de suelo colectadas principalmente al sureste del país, siendo identificadas toxinas de los tipos A, Cy F (8).

Para complementar la información disponible y ampliar el conocimiento sobre la distribución de este microorganismo en el país, se colectaron muestras de suelo y lodo en varios departamentos, principalmente de la Región Oriental, por ser ésta la más afectada, con casos confirmados o de sospecha de botulismo, además de constituirse en el área con mayor concentración de establecimientos ganaderos y población bovina.

\section{MATERIALES Y MÉTODOS}

Un total de 54 muestras de suelo y lodo fueron colectadas en 12 departamentos del Paraguay (Enumerado de 1 a 17) (Tabla 1). La mayoría (52 de las 54 muestras) provinieron de sitios ubicados al este del río Paraguay (Región Oriental) teniendo en cuenta que la mayoría de los casos confirmados y de sospecha de botulismo en bovinos ocurrió en esta región del país; sólo 2 muestras fueron obtenidas del lado oeste (Región Occidental o Chaco).

De las 54 muestras (20 de suelo y 34 de lodo) 36 fueron de establecimientos ganaderos existiendo en algunos de los mismos antecedentes de alta mortalidad en bovinos, habiendo sospecha como una de las causas el botulismo. Por ello se procedió a la colecta de algunas muestras en las proximidades de los cadáveres de los animales, ya sea de suelos como también de lagunas que eran utilizadas como fuente de agua para los bovinos. Se colectaron 9 muestras del río Paraguay, de zonas próximas a la capital, Asunción; 6 del lago Ypacaraí, de zonas situadas aproximadamente a $50 \mathrm{~km}$ de la capital y 3 de pantanos (Tabla 2).

Los procedimientos de muestreo y de examen se realizaron de acuerdo a lo descripto por Smith y Moryson (1975) (9). Los sitios para la colecta de cada muestra fueron seleccionados aproximadamente a 3 o $4 \mathrm{~km}$ uno del otro y cada una consistió en un compuesto de suelo o lodo de distintos puntos, a aproximadamente $10 \mathrm{~m}$ de distancia uno de otro. Las muestras fueron de unos $200 \mathrm{~g}$, colectadas del subsuelo; varias fueron tomadas de pasturas, en cuyo caso el pasto fue removido de la superficie, extrayéndose las muestras de suelo de una profundidad de alrededor de 5 a 10 $\mathrm{cm}$. En un establecimiento (del Dpto. Misiones) fueron obtenidas muestras de suelo en contacto con cadáveres en descomposición de 2 bovinos, siendo 
colectadas entre 20 - $50 \mathrm{~cm}$ de distancia del cadáver y bajo los mismos.

Las muestras del lago Ypacaraí y río Paraguay fueron colectadas de costas y cercanías de zonas inundadas. Posteriormente, fueron transportadas al laboratorio, donde cada muestra se dividió en porciones (para permitir la repetición del examen si fuere necesario) y se mantuvieron a $-20^{\circ} \mathrm{C}$ hasta su estudio. Para su evaluación, en cada ocasión, 10-12 muestras se tomaron del congelador y fueron descongeladas a temperatura ambiente $\left(22-28^{\circ} \mathrm{C}\right)$ durante la noche. De cada muestra se separó una submuestra de $50 \mathrm{~g}$ a la cual se añadió $50 \mathrm{ml}$ de solución amortiguadora de fosfato con gelatina (GPB) pH 7.0 en el caso de lodo. Por cada muestra de suelo de $50 \mathrm{~g}$ se agregó $100 \mathrm{ml}$ de GPB, siguiendo el método de Smith y Moryson (1977) (10). Luego se procedió a la mezcla mediante mortero y pistón, posteriormente, la fase líquida fue transferida a un cilindro de medición, dejándola en reposo durante 15-30 min a fin de permitir la sedimentación de las partículas de mayor tamaño. El sobrenadante se transfirió a un frasco estéril, y se centrifugó durante 3-5 min a 160 g para la eliminación de desechos adicionales. El sobrenadante obtenido de esta centrifugación lenta fue transferido a un frasco universal adicional, siendo centrifugado a $1.500 \mathrm{~g}$ durante $30 \mathrm{~min}$; el sobrenadante se desechó y el sedimento se dividió en dos partes iguales ( $1 \mathrm{~g}$ ), siendo inoculados en dos frascos McCartney de $25 \mathrm{ml}$ conteniendo medio de carne cocida (Difco), uno de los frascos se calentó a $60^{\circ} \mathrm{C}$ durante $1 \mathrm{~h}$ a baño María. Los frascos calentados y no calentados, se incubaron a $30^{\circ} \mathrm{C}$ durante 6 a 8 días. Luego de la incubación, se prepararon filtrados a partir del sobrenadante de cada frasco y se diluyeron 1 en 4 en (a) solución GPB, pH 6,6, según lo descripto por Bowmer para producir el "filtrado no tripsinizado", y (b) GPB, pH 6,0, conteniendo tripsina $(0,5 \%)$, incubado a $37^{\circ} \mathrm{C}$ durante $30 \mathrm{~min}$, para producir el "filtrado tripsinizado"(11). La Toxina botulínica fue detectada por inoculación intraperitoneal (dosis 0,5 ml) del sobrenadante del filtrado de cada muestra en un par de ratones blancos de 20-25 g. Los ratones fueron observados durante 4 días posteriores a la inoculación a fin de detectar sintomatología de dificultad respiratoria ("cintura de avispa") generalmente seguida de parálisis y muerte. Las muestras positivas fueron sometidas a las pruebas de seroneutralización con antisueros específicos.

Los resultados fueron analizados aplicando el método de estadística descriptiva y se evaluaron frecuencias absolutas y relativas.

\section{RESULTADOS Y DISCUSIÓN}

C. botulinum se encontró en 9 de los 12 departamentos de donde las muestras fueron colectadas (Figura 1).

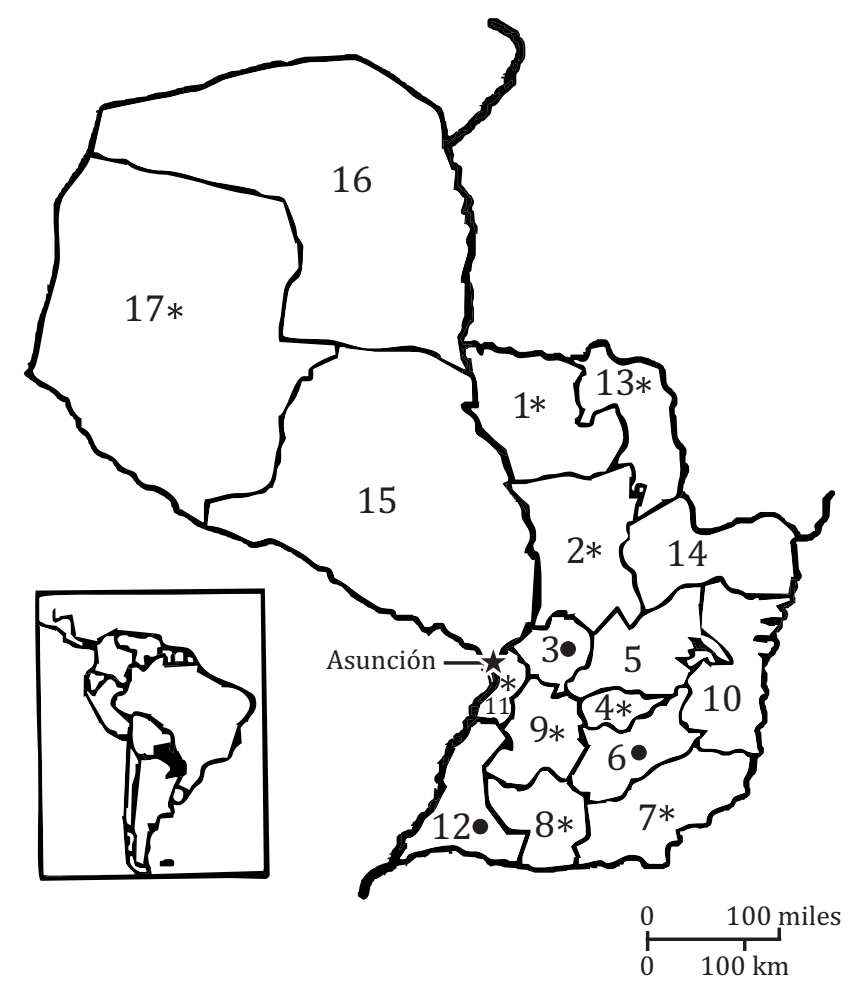

Figura 1. Departamentos del Paraguay con muestras positivas $(*)$ y negativas $(\bullet)$

\begin{tabular}{|c|c|c|c|c|}
\hline \multicolumn{2}{|c|}{ 1. Concepción(*) } & 7. Itapúa & $(*)$ & 13. Amambay \\
\hline 2. San Pedro & $(*)$ & 8. Misiones & $(*)$ & 14. Canindeyú \\
\hline 3. Cordillera & (•) & 9. Paraguarí & $(*)$ & 15. Presidente Hayes \\
\hline 4. Guairá & (*) & 10. Alto Paraná & & 16. Alto Paraguay \\
\hline 5. Caaguazú & & 11. Central & $(*)$ & 17. Boquerón \\
\hline 6. Caazapá & $(\bullet)$ & 12. Ñeembucú & $(\bullet)$ & \\
\hline
\end{tabular}

En las Tablas 1 y 2 se indican los números de los departamentos y los tipos de sitios, respectivamente con muestras positivas de acuerdo al tipo de $C$. botulinum. De las 54 muestras de suelo y lodo examinadas, en 18 (33,3\%) se demostró la presencia de $C$. botulinum; siendo el tipo A detectado en 1 muestra del Chaco; el tipo $C$ en 6 muestras; el 
Tabla 1. Número de muestras colectadas, positivas y tipos de C. botulinum en 12 departamentos del Paraguay

\begin{tabular}{|c|c|c|c|c|c|c|}
\hline \multirow{2}{*}{$\begin{array}{c}{ }^{*} \mathrm{~N}{ }^{\circ} \text { de } \\
\text { Departamento }\end{array}$} & \multirow{2}{*}{$\begin{array}{l}\text { Número de } \\
\text { muestras }\end{array}$} & \multirow{2}{*}{$\begin{array}{c}\text { Número de } \\
\text { muestras } \\
\text { positivas }\end{array}$} & \multicolumn{4}{|c|}{$\begin{array}{l}\text { Número de muestras positivas } \\
\text { por tipo de } C \text {. botulinum }\end{array}$} \\
\hline & & & A & $\mathrm{C}$ & $\mathrm{D}$ & †Desconocido \\
\hline 1 & 10 & 2 & 0 & 0 & 2 & 0 \\
\hline 2 & 5 & 1 & 0 & 1 & 0 & 0 \\
\hline 3 & 3 & 0 & 0 & 0 & 0 & 0 \\
\hline 4 & 4 & 1 & 0 & 0 & 0 & 1 \\
\hline 6 & 1 & 0 & 0 & 0 & 0 & 0 \\
\hline 7 & 3 & 1 & 0 & 1 & 0 & 0 \\
\hline 8 & 4 & 4 & 0 & 0 & 3 & 1 \\
\hline 9 & 3 & 1 & 0 & 0 & 1 & 0 \\
\hline 11 & 15 & 6 & 0 & 4 & 1 & 1 \\
\hline 12 & 2 & 0 & 0 & 0 & 0 & 0 \\
\hline 13 & 2 & 1 & 0 & 0 & 0 & 1 \\
\hline 17 & 2 & 1 & 1 & 0 & 0 & 0 \\
\hline Total & 54 & 18 & 1 & 6 & 7 & 4 \\
\hline$\%$ & 100 & 33,3 & 1,9 & 11,1 & 13,0 & 7,4 \\
\hline
\end{tabular}

tipo $\mathrm{D}$ en 7 muestras y otras 4 más resultaron positivas pero la toxina producida en los cultivos fue débil para ser tipificada.

Los resultados indican que C. botulinum, particularmente los tipos C y D se encuentran ampliamente distribuidos en la Región Oriental del país, no así los otros tipos; esto resulta de gran interés, considerando que los tipos $\mathrm{C}$ y D son los agentes causales más frecuentes de botulismo en animales.

Las muestras positivas, por una parte, constituyeron aquellas colectadas en las inmediaciones de cadáveres de bovinos, resultados que son similares a los hallazgos en Brasil, donde estudios sobre la distribución de C. botulinum alrededor de cadáveres descompuestos en sitios con antecedentes de casos de botulismo en bovinos, dieron como resultado una alta prevalencia de los tipos C y D en relación a otros tipos como A, B y G, que fueron raros (12). Tambien en muestras de suelo, de otros estudios en dicho país se detectaron los tipos $\mathrm{C}$ y D $(1,2,3)$.

En el presente estudio las muestras positivas a C. botulinum tipo D provinieron de establecimientos ganaderos donde hubieron casos confirmados o de sospecha de botulismo, causados por el tipo D en los departamentos de San Pedro y Misiones (7). El tipo D ha sido considerado como principal causa de botulismo en bovinos y la enfermedad está asociada con la aberración del apetito (pica) como resultado de la deficiencia de fósforo en pasturas $(2,13)$. El botulismo bovino ha ocurrido en similares condiciones en Brasil $(1,2)$ y Argentina (4). En Paraguay, la deficiencia de fósforo en los suelos se ha identificado en los departamentos de Paraguarí, Misiones y otras áreas donde han ocurrido casos de mortandad en bovinos (14). Y en otra investigación se detectaron bajas concentraciones de fósforo en muestras de suero bovino, particularmente en terneras lactantes, en la que la osteofagia fue frecuentemente observada en la población estudiada (15).

La presencia del tipo C se demostró en muestras colectadas en los departamentos de San Pedro, Central e Itapúa. No se disponen de publicaciones sobre casos confirmados de botulismo ocasionados por el tipo C en el país, sin embargo, fue confirmado en bovinos de varios países $(1,2,3,4,5$, $16,17)$, así como en otras especies animales, siendo causante de la mayoría de los casos de botulismo en aves $(18,19,20)$. En el Paraguay tampoco se cuenta con información acerca de la patología en otras especies distintas al bovino.

La detección del tipo A en muestras de la Región Occidental es de interés, particularmente debido a que este tipo ha sido también identificado en muestras de suelo de la Región Oriental, departamento Central, por Yamakawa et al (8). Además, se ha demostrado que ha sido causante de la 
Tabla 2. Número de muestras colectadas positivas y tipos de $C$. botulinum en muestras de diferentes sitios

\begin{tabular}{lcccccc}
\hline \multirow{2}{*}{ Sitios } & Número & Número de & & \multicolumn{2}{c}{$\begin{array}{c}\text { Número de muestras positivas } \\
\text { por tipo de C. botulinum }\end{array}$} \\
\cline { 3 - 7 } & de muestras & muestras positivas & A & C & D & *Desconocido \\
\hline Establecimientos & 36 & 13 & 1 & 2 & 7 & 3 \\
† Río & 9 & 3 & 0 & 2 & 0 & 1 \\
† Lago & 6 & 1 & 0 & 1 & 0 & 0 \\
Pantanos & 3 & 1 & 0 & 1 & 0 & 0 \\
\hline
\end{tabular}

enfermedad en bovinos de Brasil (21). En Argentina fue hallado en muestras de suelo $(5,22)$ y en muestras de cadáveres bovinos con sospecha de haber muerto a causa de botulismo (23). Por otro lado, la confirmación de la presencia del tipo A en ambas regiones del país es un llamado de alerta para la salud pública, ya que es la causa más frecuente de botulismo en humanos, particularmente el botulismo infantil, según casos reportados en varios países del mundo (24).

Los tipos B, E, F, G no fueron detectados en este estudio, aunque la presencia de los mismos fue confirmada en Brasil y Argentina (1, 3, 4, 5, 12, 21, 25). El tipo $\mathrm{F}$ se reportó en otro estudio de muestras de suelo del Paraguay por Yamakawa et al 1990 (8).

El tipo C estuvo presente en muestras de varios tipos de sitios estudiados en esta investigación (establecimientos ganaderos, pantanos, el río Paraguay y el lago Ypacaraí); sin embargo, el tipo D fue identificado solamente en muestras de los establecimientos ganaderos. El $C$. botulinum se detectó en $29,4 \%$ de muestras de lodo y $40 \%$ de muestras de suelo, resultados que contrastan con estudios realizados en el Reino Unido de Gran Bretaña, donde su presencia fue más frecuente en muestras de lodo que en suelo (12) encontrándose solo en $5 \%$ de las muestras de suelo británico (26). Los resultados señalados en este estudio probablemente se deben a que vastas superficies de Paraguay son en ocasiones afectadas por inundaciones durante las estaciones lluviosas, lo que contribuye no solo a diseminar las esporas bacterianas en el ambiente, sino también ocasiona la polución de grandes superficies con materia orgánica en descomposición, incluyendo cadáveres de animales, que proveen condiciones adecuadas para la multiplicación del microorganismo.

\section{CONCLUSIÓN}

Los hallazgos en esta investigación demuestran que las toxinas tipo C y D están ampliamente distribuidas en la Región Oriental del país. La presencia del tipo $\mathrm{C}$ en una diversidad de sitios como establecimientos ganaderos, lago Ypacaraí, río Paraguay y pantanos es relevante, debido a que ese tipo de $C$. botulinum está relacionado a brotes de botulismo, no solo en bovinos, sino también en aves y otras especies animales.

Se destaca que el tipo D se detectó solamente en muestras obtenidas en establecimientos ganaderos con antecedentes de afección de la enfermedad y en muestras colectadas de proximidades de cadáveres bovinos. Aunque estos hallazgos no confirman que los casos ocurridos hayan sido causados por C. botulinum tipo D, su presencia en los establecimientos ganaderos representa un riesgo potencial y sugiere que pudo haber sido uno de los desencadenantes de algunos brotes de la enfermedad en el país, teniendo en cuenta además, el clima, con frecuentes lluvias e inundaciones de grandes superficies de los establecimientos y por ende abundante material orgánico animal y vegetal en descomposición que proporcionan condiciones favorables para la germinación de las esporas y producción de toxinas, que junto con una limitada o ausencia de suplementación mineral, son factores de riesgo importantes que contribuyen a la aparición del botulismo en animales.

El estudio amplía el conocimiento sobre la distribución y los tipos existentes en el país, particularmente en la Región Oriental. A pesar de haber sido examinado un escaso número de 
muestras de la Región Occidental, donde es necesaria una mayor investigación sobre la presencia de $C$. botulinum, se destaca la confirmación del tipo A.

\section{AGRADECIMIENTOS}

Al Dr. Antonio Rodríguez Sánchez y a la Dra. Jorgelina Brizuela de Heisecke por brindar informaciones (no publicadas) relacionadas a la enfermedad en el Paraguay; a los colegas de la Facultad de Ciencias Veterinarias de la Universidad Nacional de Asunción y del Ministerio de Agricultura y Ganadería por su colaboración en la colecta de muestras.

\section{BIBLIOGRAFÍA}

1. Tokarnia CH, Langenegger J, Langenegger $\mathrm{CH}$, Veras de Carvalho E. Botulismo em bovinos de Piauí, Brasil. Pesqui. Agropecu. Bras. $1970 ; 5: 465-472$.

2. Döbereiner J, Tokarnia CH, Langenegger J, Dutra, IS. Epizootic botulism of cattle in Brazil. Dtsch. Tierarztl. Wochenschr.1992; 99:188-190.

3. Dutra IS, Döbereiner JR, Rosa IV, Souza LA, Nonato M. Surtos de botulismo em bovinos no Brasil à ingestão de água contaminada. Pesq. Vet. Bras. 2001; 21(2):43-48.

4. Zurbriggen MA, Soni CA, Pasini MI, Benitez MG, Homse CA, Báez Kohn RA, et al. Botulismo bovino en la Provincia de Corrientes (Argentina). Veterinaria Argentina. 1986; 3:751-755.

5. Fernández RA, Cicarelli AS, Arenas GN, Giménez DF. Clostridium botulinum tipos D y A en materiales de necropsia de bovinos afectados por el Mal de Aguapey. Rev Argent Microbiol. 1989; 21:47-53.

6.Cameron CM. A brief history of botulism in South Africa Onderstepoort Journal of Veterinary Research, 2009; 76:11-12.

7. Brizuela CM. Bovine botulism in Paraguay. Trop Anim Health Prod.1996; 28 (3): 221-222.

8. Yamakawa K, Hayashi T, Kamiya S, Yoshimura K, Nakamura S. Clostridium botulinum in soil of Paraguay. Jpn J Med Sci Biol. 1990; 43:19-21.

9. Smith GR, Moryson CJ. Clostridium botulinum in the lakes and waterways of London. Journal of Hygiene. 1975; 75:371-379.

10. Bowmer EJ. Preparation and assay of the international standards for Clostridium botulinum, types A, B, C, and E antitoxins. World Health Organization. 1963; 29: 701-709.

11. Smith GR, Moryson CJ. A comparison of the distribution of Clostridium botulinum in soil and lake mud. Journal of Hygiene. 1977; 78:39-41.

12. De Souza AM, y Langenegger J. Esporos de Clostridium botulinum em tornos de cadáveres descompostos de bovinos em pastagens no sul de Goiás. Pesq. Vet. Bras. 1987; 7:17-22.
13. Theiler A, Viljoen PR, Green, HH, Dutoit PJ, Meier H, Robinson EM. Lamsietke (Parabotulinum) in cattle in South Africa. 11th and 12th Report of the Director of Veterinary Education and Research, Union of South Africa, Department of Agriculture Journal. 1927; 2: 819-821.

14. Okamoto M, Rojas S, Castellani P, Rosthoj S, Morel G, Branda de Oka B, et al. Estudio de minerales en suelo y praderas naturales en el Paraguay. Revista Veterinaria. 1987; 30:19-23.

15. Gray D, Acosta L, Garay S, King C, Digby K, Ferreira N, et al. Niveles de minerales en sangre de bovinos de carne. Ministerio de Agricultura y Ganadería, Boletín de Investigación. 1978; (14): 1-19.

16. Baldassi L, Hipolito M, S. C. Portugal MA, Borgheresi Calil EM, Procaci Moulin AA, de Cássia Pires D. Botulismo bovino: comprovação laboratorial do diagnóstico clínico, período 19861989. Rev Saude Publica. 1991; 25 (5):371-374.

17. Maboni F, Monego F, Dutra I, Matiuzzi da Costa MM, Castagna de Vargas A. Ocorrência de botulismo em bovinos confinados no Rio Grande do Sul. Ciencia Animal Brasilera. 2010; 11(4): 962965.

18. Defilippo F, Luppi A, Maioli G, Marzi D, Fontana MC, Paoli F, et al. Outbreak of type $C$ botulism in birds and mammals in the Emilia Romagna region, northern Italy. Journal Will Disease. 2013; 49(4):1042-1046.

19. Faria Lobato FC, Salvarani FM, Silveira Silva RO, Antunes de Assis R, do Lago LA, de Carvalho Filho MB, et al. Botulismo tipo C em perus em Minas Gerais, Brasil. Ciência Rural, Santa Maria. 2009; 39(1): 272-274

20. Sharpe AE, Sharpe EJ, RyanED, ClarkeH J, McGettrick SA. Outbreak of type $\mathrm{C}$ botulism in laying hens. Veterinary Record 2011; 168: 669

21. Schocken-Iturrino RP, Avila FA, Berchielli SCP, Nader A. First case of type A botulism in zebu (Bosindicus). Veterinary Record. 1989; 126: 217-218.

22. Lúquez C, Bianco MI, Jong LIT, Sagua MD, Arenas GN, Ciccarelli AS, et al. Distribution of Botulinum Toxin-Producing Clostridia in Soils of Argentina. Applied Environ. Microbiology. 2005; 71(7): 4137-4139.

23. Giménez DF, Ciccarelli AS. Clostridium botulinum in Argentina: presente y futuro. Rev Asoc Argent Microbiol. 1976; 8: 82-91.

24. Koepke R, Sobel J, Stephen S, Arnon SS. Reported Infant Botulism Cases According to Continent and Country, 1976-2006. Pediatrics. 2008; 122 (1): 73-82.

25. Giménez DF, Ciccarelli AS. Clostridium botulinum type F in soil of Argentina. Applied Microbiology. 1968; 16:732.

26. Smith GR, Young AM. Clostridium botulinum in British soil. Journal of Hygiene. 1980; 85: 271-274. 